\title{
Development and characterisation of injection moulded, all-polypropylene composites
}

\author{
A. Kmetty ${ }^{1,2 *}$, T. Tábi ${ }^{1,2}$, J. G. Kovács ${ }^{1}$, T. Bárány ${ }^{1}$ \\ ${ }^{1}$ MTA-BME Research Group for Composite Science and Technology, Müegyetem rkp. 3., H-1111 Budapest, Hungary \\ ${ }^{2}$ Department of Polymer Engineering, Faculty of Mechanical Engineering, Budapest University of Technology and \\ Economics, Müegyetem rkp. 3., H-1111 Budapest, Hungary
}

Received 16 July 2012; accepted in revised form 16 September 2012

\begin{abstract}
In this work, all-polypropylene composites (all-PP composites) were manufactured by injection moulding. Prior to injection moulding, pre-impregnated pellets were prepared by a three-step process (filament winding, compression moulding and pelletizing). A highly oriented polypropylene multifilament was used as the reinforcement material, and a random polypropylene copolymer (with ethylene) was used as the matrix material. Plaque specimens were injection moulded from the pellets with either a film gate or a fan gate. The compression moulded sheets and injection moulding plaques were characterised by shrinkage tests, static tensile tests, dynamic mechanical analysis and falling weight impact tests; the fibre distribution and fibre/matrix adhesion were analysed with light microscopy and scanning electron microscopy. The results showed that with increasing fibre content, both the yield stress and the perforation energy significantly increased. Of the two types of gates used, the fan gate caused the mechanical properties of the plaque specimens to become more homogeneous (i.e., the differences in behaviour parallel and perpendicular to the flow direction became negligible).
\end{abstract}

Keywords: polymer composites, all-polypropylene composites, injection moulding

\section{Introduction}

Recently, environmental protection and recycling issues have become important. Environmentally conscious and new materials are spreading widely. Development of self-reinforced materials and composites (matrix and reinforced materials belonging to the same polymer family) began in the 1970s and now are intensively researched [1]. Originally, in situ self-reinforcing parts were made from a singlecomponent material. These techniques, e.g., selfreinforced extrusion and self-reinforced injection moulding (both shear-controlled orientation in injection moulding (SCORIM) [2-3] and vibration injection moulding (VIM) [4]), were used successfully. The essence of these techniques was the orientation of the molecular chain relative to the shear load to produce a shish-kebab structure [5]. The main disadvantage of these techniques was the difficulty in designing the reinforcement structure. From the 1990s until present, multi-step production of self-reinforcing parts has become widespread. Three methods were used to produce self-reinforced materials/composites [6]: hot compaction (singlecomponent self-reinforced materials (SRM)) [7-9], consolidation of coextruded tapes [10] and filmstacking methods (multi-component SRM) [1118]. The geometries of the products prepared with these techniques are limited because only sheet preproduct can be manufactured, and thereafter it can be shaped by thermoforming. However, large-scale production of SRPCs has become highly preferred in the last $1-3$ years.

\footnotetext{
${ }^{*}$ Corresponding author, e-mail: kmetty@pt.bme.hu

(C) BME-PT
} 
The aim of this paper is to demonstrate that it is possible to injection mould all-polypropylene composites and to determine the effects of the reinforcing fibre content and the type of gate on static tensile and dynamic mechanical properties and shrinkage of the composite plaque.

\section{Preliminary tests}

To produce products with complex 3D geometry, injection moulding is a suitable technique. To process all-polypropylene composites by injection moulding, intensive preliminary tests have been performed. Matrix and reinforcement materials, pellets for injection moulding and a processing method were developed. Random ethylene-polypropylene copolymer (rPP) and highly oriented polypropylene homopolymer (hPP) reinforcement were characterised by mechanical and morphological tests. First, the matrix and the reinforcement were mixed in a powder mixer. The mix was subsequently injection moulded with an Arburg Allrounder 320C 700-290 machine. The preliminary results showed that the hPP multifilament became roughened and formed agglomerates (due to electrostatic charge), and a cold slug formed that blocked the standard flat nozzle, which had $2 \mathrm{~mm}$ diameter hole. The reinforcement fibre content could not be guaranteed, and even distribution of reinforcement fibres could not be achieved. The standard flat nozzle has been replaced with a heated flat nozzle with $4 \mathrm{~mm}$-diameter hole to avoid cold slug formation. Next, to avoid agglomeration of reinforcing fibres, extrusion coating was applied prior to injection moulding; one or two bobbins of hPP multifilament were used, and these were continuously coated in a special extrusion die by molten matrix material made of rPP. The coated multifilament was granulated into $4,10 \mathrm{~mm}$ long cylindrical pellets and used for injection moulding. This pre-product can be injection moulded at different temperature between $150-180^{\circ} \mathrm{C} .160^{\circ} \mathrm{C}$ was the lowest temperature where stable technology (without cold slug) can be achieved. At this temperature the thermoplastic reinforcement did not melt during manufacturing. The mechanical tests revealed that a slight reinforcing effect can be detected. The microscopy images showed that neither the distribution of the single fibres nor the impregnation of matrix material was perfect. These problems must arise from the improper impregnation of the coated pre-product; the impregnation process required improvement. Hence, the goal of this paper is to demonstrate the improved processability of allpolypropylene composites by injection moulding, including preparation of the pre-product and the injection moulding.

\section{Materials, processing and testing}

\subsection{Materials}

Highly oriented polypropylene homopolymer (hPP) multifilament (Stradom S. A., Czestochowa, Poland) was used as reinforcement. This reinforcing multifilament has a melting temperature of $173^{\circ} \mathrm{C}$ (as determined by DSC from the first melting curve with a heating rate of $10^{\circ} \mathrm{C} / \mathrm{min}$ ); a yield stress of $581 \pm 30 \mathrm{MPa}$; tensile modulus of $6432 \pm 490 \mathrm{MPa}$ (measured by single-fibre tensile tests) and the single fibre diameter of $40.1 \pm 1.8 \mu \mathrm{m}$. The multifilament was sized with carboxylic acid by the producer. Random ethylene-polypropylene (rPP) copolymer (Tipplen R959A, TVK Nyrt., Tiszaújváros, Hungary) was used as the matrix material. From the initial rPP granules, a $50 \mu \mathrm{m}$ thick film was produced using an extrusion film blowing technique. The melting temperature of the matrix was $150^{\circ} \mathrm{C}$ (as determined by DSC from the first melting curve with a heating rate of $10^{\circ} \mathrm{C} / \mathrm{min}$ ).

\subsection{Pre-impregnated material preparation}

The matrix film and the reinforcing hPP multifilament were laminated pretensioned onto an aluminium core in a filament winding process using the film-stacking method, which resulted in unidirectionally aligned (UD) fibres, shown in Figure 1a. All-polypropylene composite (all-PPC) sheets with thicknesses of $1.7 \mathrm{~mm}$ and varying nominal reinforcing multifilament content (50, 60, 70 and $80 \mathrm{wt} \%)$ were produced by compression moulding, shown in Figure 1b. For the sandwich structure 9 layers were applied. The nominal reinforcement was controlled by the number of the applied matrix foils. For $50 \mathrm{wt} \%$ four layer matrix foil and one layer reinforcement was used. To increase the reinforcement content number of the matrix foils was decreased one by one. A temperature of $180^{\circ} \mathrm{C}$ was applied during the consolidation process. The filament-wound, filmstacked package was inserted in between the preheated moulds and held for $240 \mathrm{~s}$ without pressure, was compressed for $240 \mathrm{~s}$ under a pressure of $5.26 \mathrm{MPa}$ and finally was cooled to $45^{\circ} \mathrm{C}$ (under pressure). Actually the processing temperature was 

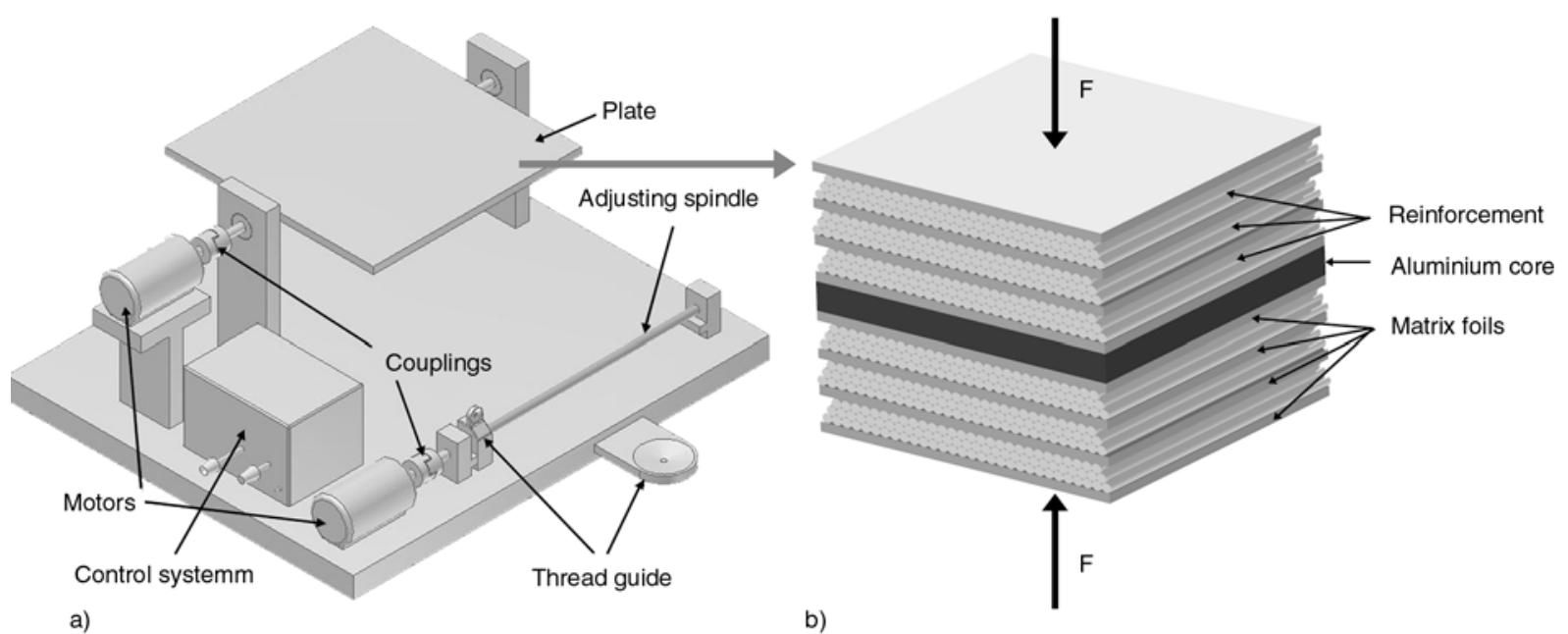

Figure 1. Preparation of unidirectional all-PP composite, with filament winding (a) and with subsequent compression moulding (b) (theoretical lay-up)

higher than the melting temperature of the reinforcement but, due to the high pressure, this value shifted towards higher value (similar the self-reinforced extrusion technique [19]) and the thermoplastic reinforcement did not melt. The consolidated plates were cut into 5 (wide) $\times 5$ (length) $\mathrm{mm}^{2}$ sections for injection moulding. The length dimension of these cut pieces determined the length of the reinforcing fibres.

\subsection{Injection moulding}

From pre-impregnated pellets plaque specimens measuring $80 \times 80 \times 2 \mathrm{~mm}$ in dimension were injection moulded with varying amounts of reinforcing multifilament $(50,60,70$ and $80 \mathrm{wt} \%)$. The production occurred on an Arburg Allrounder 370S 700290 injection moulding machine with a heated, flat nozzle with holes measuring $4 \mathrm{~mm}$ in diameter (parameters listed in Table 1). In the mould, both a

Table 1. Injection moulding parameters

\begin{tabular}{|l|c|}
\hline \multicolumn{1}{|c|}{ Injection moulding parameters } & Value \\
\hline Injection volume $\left[\mathrm{cm}^{3}\right]$ & 50 \\
\hline Injection rate $\left[\mathrm{cm}^{3} / \mathrm{s}\right]$ & 50 \\
\hline Injection pressure $[\mathrm{bar}]$ & $800 \pm 200$ \\
\hline Switch over point $\left[\mathrm{cm}^{3}\right]$ & 10 \\
\hline Holding pressure $[\mathrm{bar}]$ & 500 \\
\hline Holding time $[\mathrm{s}]$ & 10 \\
\hline Residual cooling time $[\mathrm{s}]$ & 15 \\
\hline Screw rotational speed $[\mathrm{m} / \mathrm{min}]$ & 15 \\
\hline Back pressure $[\mathrm{bar}]$ & 20 \\
\hline Decompression volume $\left[\mathrm{cm}^{3}\right]$ & 5 \\
\hline Decompression rate $\left[\mathrm{cm}^{3} / \mathrm{s}\right]$ & 5 \\
\hline Melt temperature $\left[{ }^{\circ} \mathrm{C}\right]$ & 160 \\
\hline Mould temperature $\left[{ }^{\circ} \mathrm{C}\right]$ & 40 \\
\hline
\end{tabular}

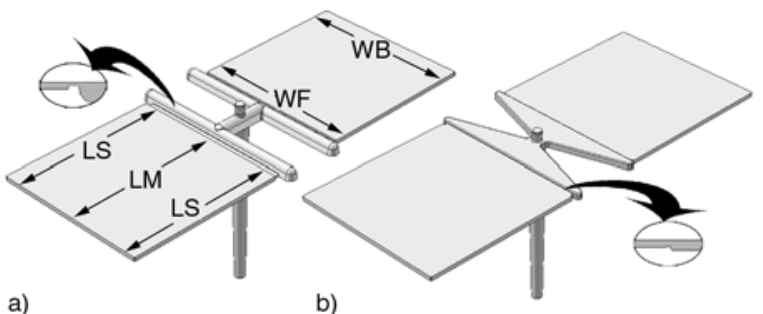

Figure 2. Plaque specimens with a conventional film gate along with shrinkage measurement positions (a) and a fan gate (FG) (b). Dimensional abbreviations [mm] are as follows: LM - length dimension at the middle; LS - length dimension at the side; WE - width dimension at the front; WB width dimension at back.

conventional film gate measuring $1 \mathrm{~mm}$ in thickness and a fan gate (FG) measuring $2 \mathrm{~mm}$ in thickness were used (Figure 2).

\subsection{Specimens and their testing}

Static tensile tests

Static tensile tests were performed on compressionmoulded sheets $(20 \times 150 \mathrm{~mm}$; in parallel to the fibre direction) and injection moulding plaque specimens. Dumbbell-shaped specimens (EN ISO 8256 Shape 3) were cut from injection moulding plaque specimens by water jet cutting parallel and perpendicular to the flow direction (Figure 3). The tensile tests were carried out by a universal ZWICK Z020 tensile machine according to the standard EN ISO 527. The cross-head speed was set to $5 \mathrm{~mm} / \mathrm{min}$, and each test was performed at room temperature $\left(24^{\circ} \mathrm{C}\right)$; at least 5 specimens from each material were tested. 


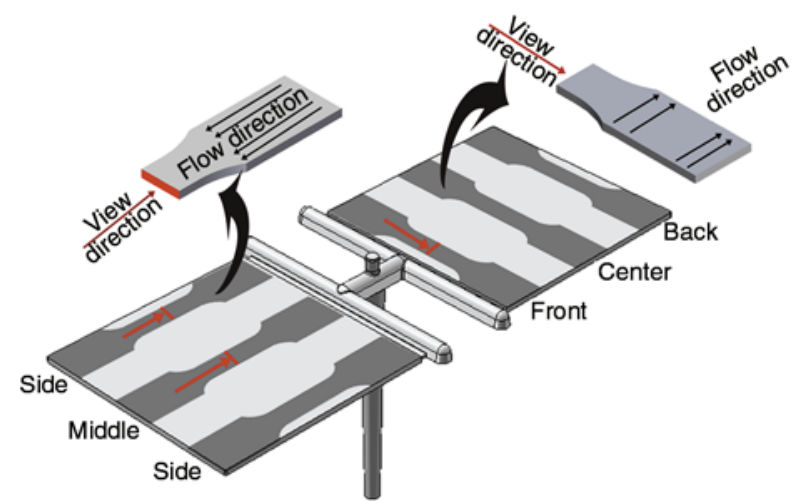

Figure 3. Preparation of dumbbell specimens from the plaque specimens in the parallel and perpendicular to the flow directions. The red lines show the positions at which the cross-sections of the injection moulding specimens were analysed by light microscopy.

\section{Instrumented falling weight impact tests}

Instrumented falling weight impact (IFWI) tests were performed on a Fractovis 3789 (Ceast, Italy) machine with the following settings: $131.84 \mathrm{~J}$ maximal energy; $20 \mathrm{~mm}$ dart diameter; $40 \mathrm{~mm}$ support rig diameter; $13.62 \mathrm{~kg}$ dart weight; and $1 \mathrm{~m}$ drop height. The samples were tested at room temperature $\left(24^{\circ} \mathrm{C}\right)$ and at $-30^{\circ} \mathrm{C}$; at least 10 specimens were tested.

\section{Dynamic mechanical analysis}

Dynamic mechanical analysis (DMA) tests were performed on a DMA Q800 machine in a 3-point bending arrangement with the following parameters: frequency: $1 \mathrm{~Hz}$; temperature range: -100 to $150^{\circ} \mathrm{C}$; amplitude: $0.16 \mathrm{~mm}$; heating rate: $5^{\circ} \mathrm{C} / \mathrm{min}$. Specimens $60 \times 10 \times 2 \mathrm{~mm}$ in dimension, which were cut in the flow direction from the plaque specimens (Figure 3 'Side'), were used for these tests.

\section{Shrinkage tests}

To describe the effect of the thermoplastic reinforcement on the shrinkage of the injection moulded products shrinkage tests were performed. Shrinkage was measured at different times $(1,4,24,48$, and $168 \mathrm{~h}$ ) and positions on the plaque specimens by digital calliper after injection moulding (cf. Figure 2).

\section{Light microscopy}

Light microscopy (LM) images were taken from the polished cross sections of injection moulding specimens in parallel and perpendicular to the flow directions by an Olympus BX51M machine. Cross sections were cut from injection moulding specimens and were embedded in epoxy resin (Figure 3). After the samples were prepared, they were polished in a Struers polisher in four steps using 320-, 1000-, 2400- and 4000-grit SiC papers and water as a lubricant.

\section{Scanning electron microscopy (SEM)}

Scanning electron microscopy micrographs were taken from fracture surfaces with a Jeol JSM-6380LA microscope. The samples were sputter-coated with gold alloy.

\section{Results and discussion}

\subsection{Static tensile tests}

The mechanical properties of the compressionmoulded sheets (parallel to the fibres) are shown in Figure 4.

Based on the results in Figure 4, it is obvious that using this filament winding and compression moulding technique can significantly increase the tensile properties. The yield stress and tensile modulus values increase linearly with increasing nominal fibre content. These results are in close agreement with previously published results for all-polypropylene composites produced by a film-stacking process [5]. The yield stress (related to maximum tensile force) of injection moulding all-PP composite is shown in Figure 5.

Yield stress increases in the flow direction with increasing nominal fibre content of the composites until the fibre content reaches $70 \mathrm{wt} \%$. Composites with $70 \mathrm{wt} \%$ fibre reinforcement produced the largest yield stress value, $\sim 38 \mathrm{MPa}$, which corresponds to a $52 \%$ improvement compared to the matrix material. At $80 \mathrm{wt} \%$ nominal fibre content, the yield stress is

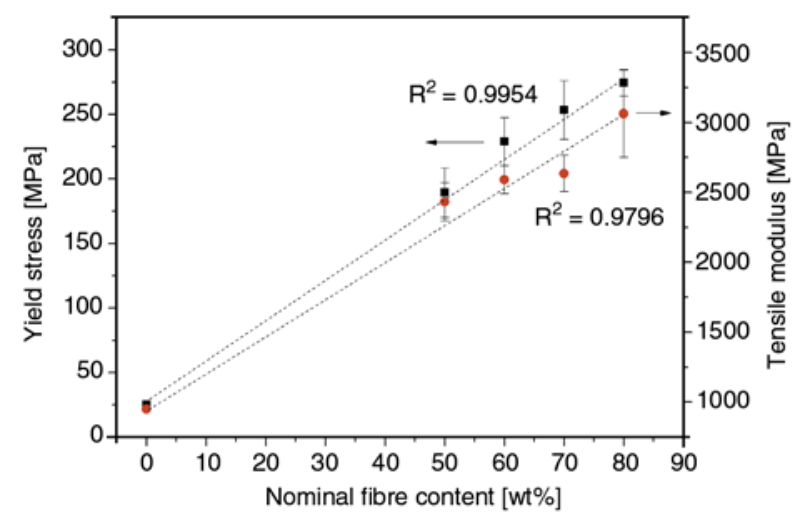

Figure 4. Yield stress and the tensile modulus of the compression-moulded all-PP composite sheets as a function of nominal fibre content 

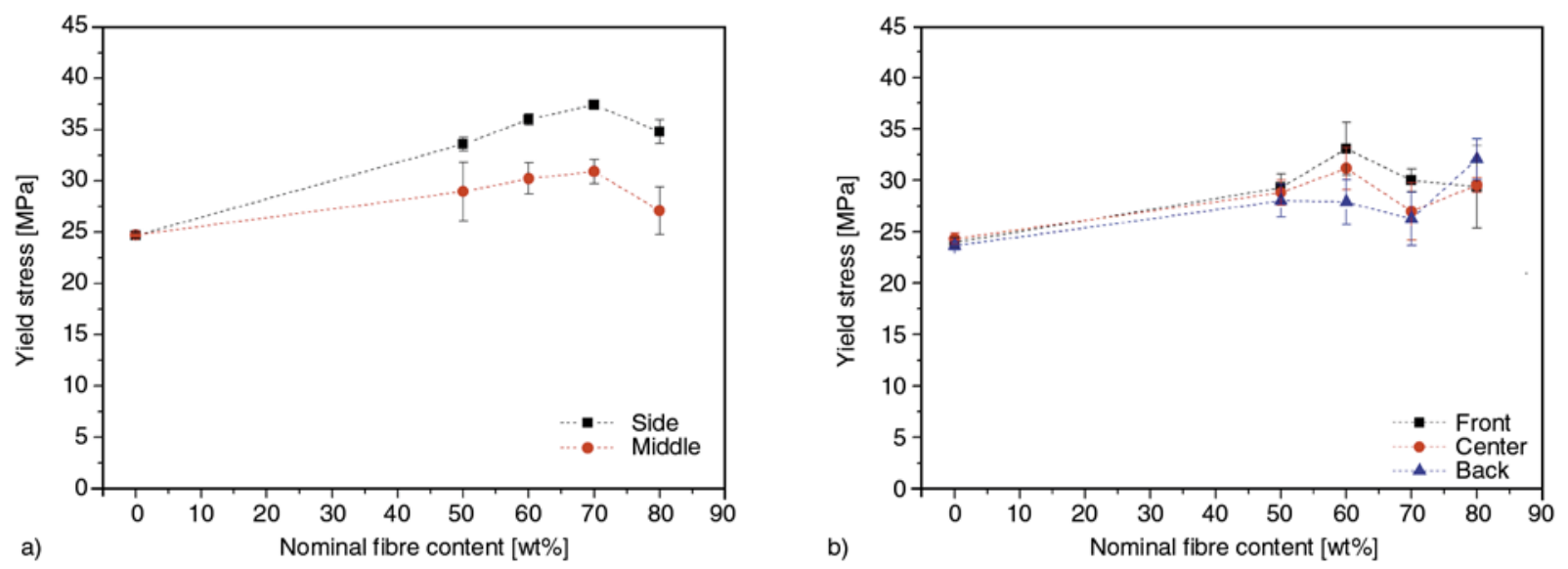

Figure 5. Yield stress of the all-PP composite parallel (a) and perpendicular (b) to the flow direction
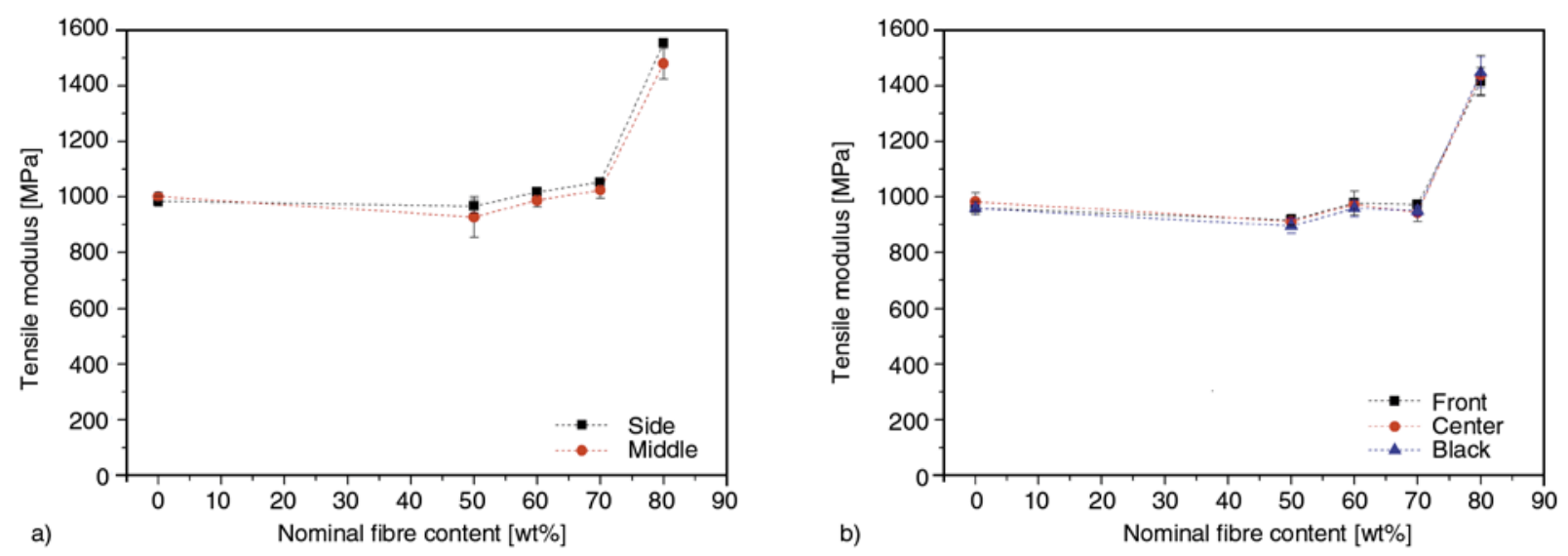

Figure 6. Tensile modulus of the all-PP composite in parallel (a) and perpendicular (b) to the flow directions

slightly lower, which is attributed to the improper consolidation of the composite structure. If analysing the filling pattern mechanical test results followed the expectations. Samples taken from the middle of the plaques had a lower yield stress than those taken from the side. This effect is caused by the orientation of the fibres inside the specimens. A slight deviation in yield stress is observed in perpendicular to the flow direction.

The tensile modulus remained constant with increasing nominal fibre content of the composites until the fibre content reached $70 \mathrm{wt} \%$, after which the modulus increased markedly (Figure 6). Increased tensile modulus is due to considerably more single fibres being aligned parallel to the load direction. This observation is also confirmed by LM (cf. Figure 11 and 12) and SEM micrographs (cf. Figure 14).

Table 2 lists the effect of the gate types on the mechanical properties. With a fan gate, the deviation in properties across the three zones of specimens decreased, i.e., the mechanical behaviours became more similar. Using the fan gate, the filling patterns became more even. In perpendicular to the flow direction, the yield stress increased compared to the one injected with film gate.

The tensile modulus in the flow direction did not change, but perpendicular to the flow direction, it

Table 2. Effect of the gate type on the yield stress and tensile modulus of all-PP composite in parallel (a) and perpendicular (b) to the flow directions (FG: fan gate)

\begin{tabular}{|l|c|c|c|c|c|c|c|c|}
\hline \multirow{2}{*}{ Section } & \multicolumn{4}{|c|}{ Yield stress [MPa] } & \multicolumn{4}{c|}{ Tensile modulus [MPa] } \\
\cline { 2 - 9 } & Matrix & Matrix (FG) & $\mathbf{8 0} \mathbf{w t \%}$ & $\mathbf{8 0}$ wt\% (FG) & Matrix & Matrix (FG) & $\mathbf{8 0}$ wt\% & $\mathbf{8 0}$ wt\% (FG) \\
\hline SIDE & $24.7 \pm 0.2$ & $26.3 \pm 0.1$ & $34.8 \pm 1.1$ & $34.8 \pm 1.3$ & $984.6 \pm 17.4$ & $939.4 \pm 194.9$ & $1554.4 \pm 11.5$ & $1518.9 \pm 12.1$ \\
\hline MIDDLE & $24.7 \pm 0.4$ & $25.5 \pm 1.1$ & $27.1 \pm 2.3$ & $30.4 \pm 1.8$ & $1000.8 \pm 16.3$ & $880.0 \pm 127.0$ & $1479.6 \pm 55.5$ & $1456.2 \pm 44.3$ \\
\hline FRONT & $24.0 \pm 0.5$ & $26.0 \pm 0.3$ & $29.4 \pm 4.0$ & $36.6 \pm 3.7$ & $959.4 \pm 23.5$ & $905.4 \pm 104.4$ & $1415.8 \pm 49.1$ & $1635.5 \pm 125.8$ \\
\hline CENTER & $24.3 \pm 0.6$ & $26.0 \pm 0.4$ & $29.5 \pm 0.7$ & $36.2 \pm 2.7$ & $982.6 \pm 32.9$ & $1096.1 \pm 117.5$ & $1437.1 \pm 72.8$ & $1594.5 \pm 43.1$ \\
\hline BACK & $23.6 \pm 0.4$ & $26.4 \pm 0.4$ & $32.0 \pm 2.0$ & $34.9 \pm 2.4$ & $958.4 \pm 12.8$ & $1154.5 \pm 33.5$ & $1447.7 \pm 55.5$ & $1624.7 \pm 39.4$ \\
\hline
\end{tabular}


increased up to $1600 \mathrm{MPa}$, due to lower friction heat in the gate zone.

\subsection{Instrumented falling weight impact tests}

To analyse the effect of reinforcing fibre content and gate type on the energy-absorbing capacity of the injection moulding plaque specimens, instrumented falling weight impact tests were performed. Typical force-time curves of the composites are shown in Figure $7 \mathrm{a}$.

These results show that the maximum of the forcetime curves increase with increasing fibre content of the composites. Figure $7 \mathrm{~b}$ shows the perforation energy (impact energy related to the thickness) of all-PP composite and matrix specimens. These results show that with increasing fibre content of up to $60 \mathrm{wt} \%$, the perforation energy increases. Above that value, the perforation energy $(\sim 3.5 \mathrm{~J} / \mathrm{mm})$ remains constant. Using a fan gate led to higher perforation energy (above $6 \mathrm{~J} / \mathrm{mm}$ ) compared to the conventional film gate which assumed to the better filling patterns. Analysing the effect the testing temperature, significant difference can be seen between the results at 24 and $-30^{\circ} \mathrm{C}$ than the matrix materials. It seems that the all-PP composites are more sensitive to the temperature. The perforation energy of all-PP composite was compared to the conventional polypropylene homopolymer material (Tipplen PP H388F, TVK Nyrt., Tiszaújváros, Hungary,); value obtained is in accordance with the literature [20]. It can be concluded that fibre reinforcement increases the perforation energy significantly compared to the matrix. The perforation energy can be increased by up to $1200 \%$ compared to the conventional raw material.
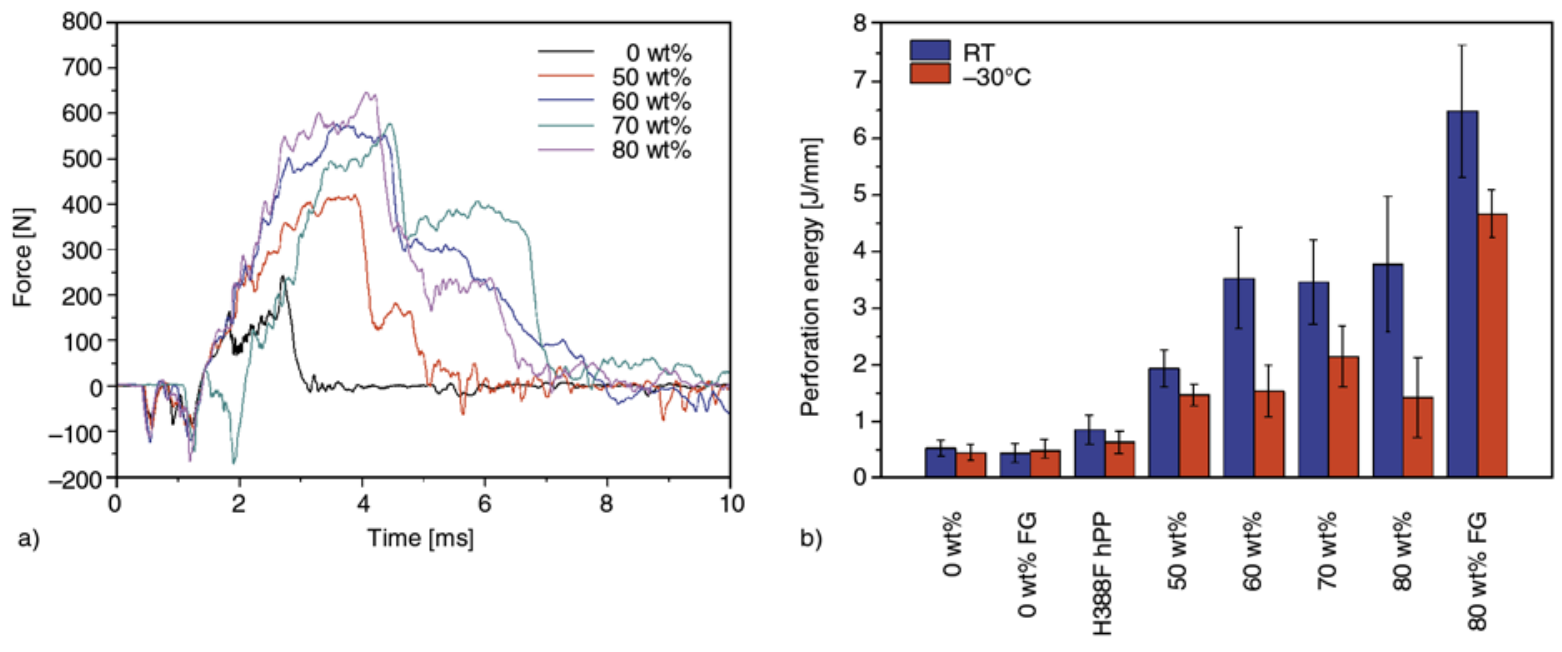

Figure 7. Force-time curves of the all-PP composites at $24^{\circ} \mathrm{C}$ (a) and perforation energy of all-PP composite, matrix and a PP homopolymer (H388F) (FG: fan gate)
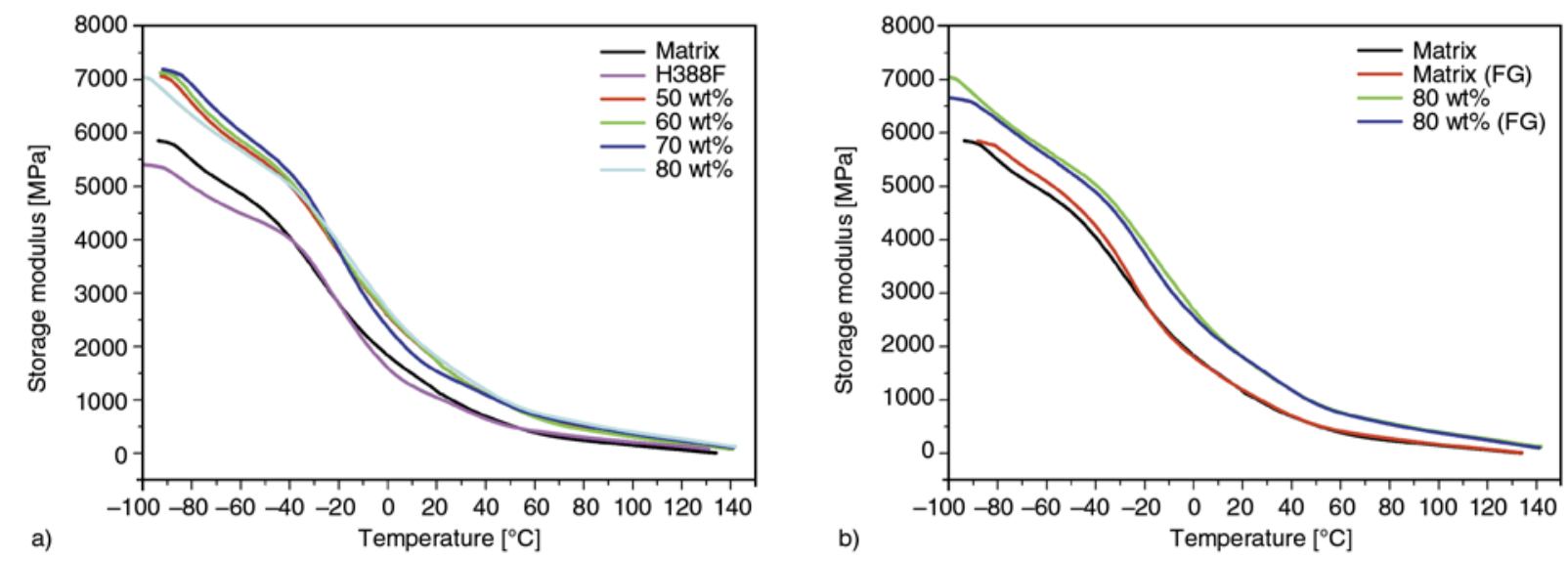

Figure 8. Storage modulus of raw materials and composites with varying fibre content with a conventional film gate (a) and a fan gate $(\mathrm{FG})(\mathrm{b})$ 


\subsection{Dynamic mechanical analysis}

Dynamic mechanical analysis was also used to show the reinforcing effect of the fibres. The storage modulus $\left(E^{\prime}\right)$ curves are shown in Figure 8.

The composites have a higher storage modulus compared to those of the matrix and commercially available PP homopolymer. While fibre reinforcement typically leads to a higher storage modulus, increasing the fibre content did not significantly affect this parameter. Replacing the conventional film gate with a fan gate did not affect the storage modulus. Upon analysis of the glass transition temperature $\left(T_{\mathrm{g}}\right.$, derived from the maximum peak of $\tan \delta$ curves), a slight shift to higher temperature can be observed (from $-14.3^{\circ} \mathrm{C}$ (matrix) to $-8.1^{\circ} \mathrm{C}$ $(80 \mathrm{wt} \%)$ ) with increasing reinforcing fibre content (i.e., increasing homopolymer content).

\subsection{Shrinkage tests}

Shrinkage of the injection moulding specimens is shown in Figure 9.

Shrinkage of thermoplastic fibre-reinforced composite increased in all directions compared to the matrix material, which is in contrast to the shrinkage behaviour of conventional fibre-reinforced composites (e.g., glass fibre) where the reinforcement in flow direction decreased the shrinkage. This effect is attributed to the relaxation of the thermoplastic
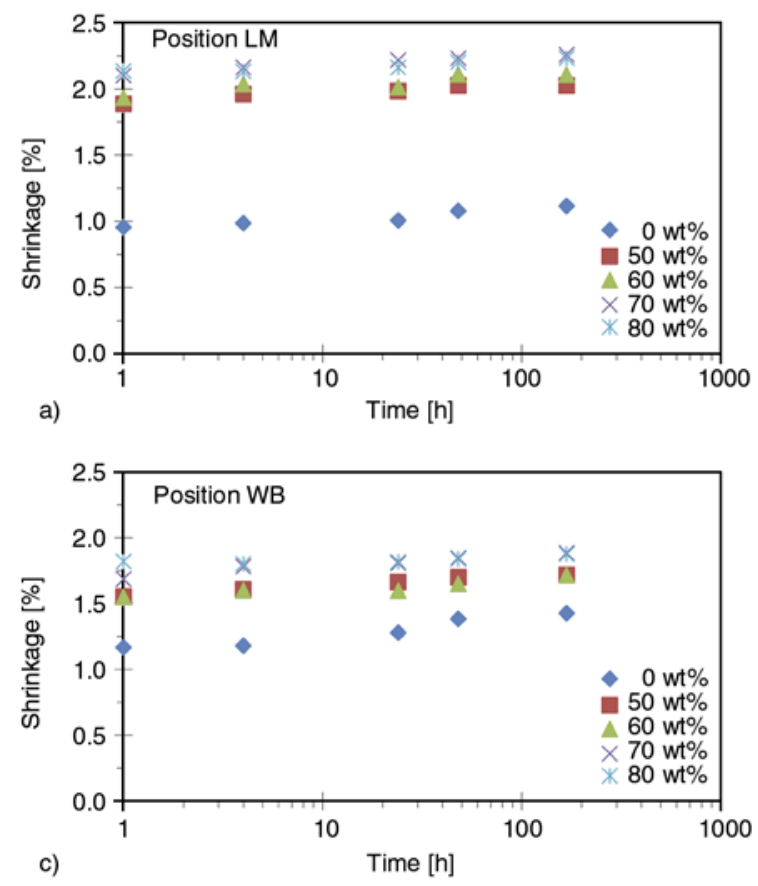

fibre. Shrinkage of the matrix material is approximately $1 \%$, which is in agreement with the literature [21]. Increasing the thermoplastic reinforcing fibre content increased the shrinkage. The greatest shrinkage occurred parallel to the flow direction at the middle of the specimen. As expected, the least shrinkage was observed near the gate due to the local pressure. Despite increased technological shrinkage (measured $1 \mathrm{~h}$ after injection) in fibrereinforced composites, subsequent post shrinkage does not differ from that in unreinforced composites. Thus, calculating the proper shrinkage for the mould construction could make the part dimensions stable over time. Plotting the results an exponential relation between technological shrinkage and fibre content can be deduced (Figure 10). One can see that the technological shrinkage is different parallel and perpendicular to the flow direction.

The shrinkage of the all-polypropylene composites used in this study can be calculated by the following Equation (1):

$S(t)=C_{1} \cdot \mathrm{e}^{-\mathrm{C}_{2}\left(1-\frac{\Phi}{100}\right)}+m \cdot \log (t)$

where $S(t)$ is the shrinkage of the composite in time and direction, $C_{1}$ is a constant which is proportional to the relaxation of the fibres, $C_{2}$ is a constant which is proportional to the fibre orientation in the speci-
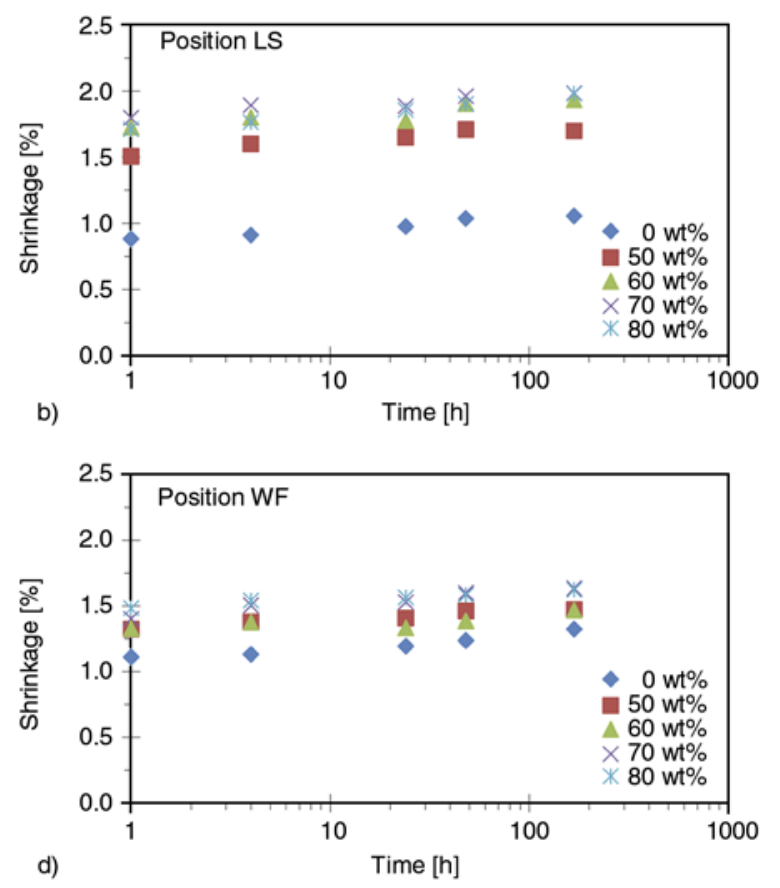

Figure 9. Shrinkage of all-PP composite specimens in different directions LM: Length Middle (a), LS: Length Side (b), WB: Width Back (c), WF: Width Front (d) 

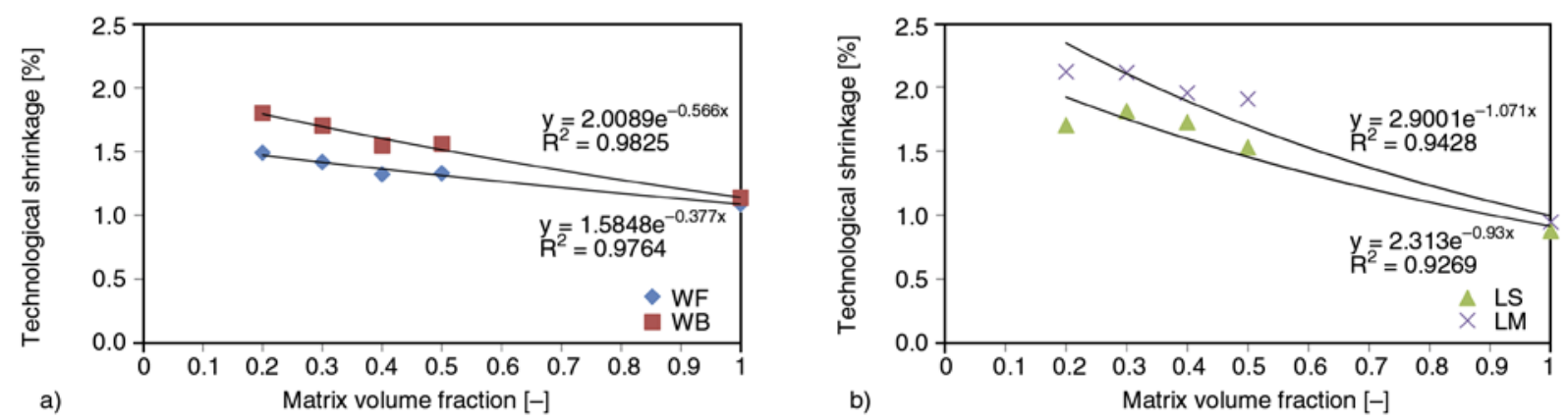

Figure 10. Technological shrinkage of the all-PP composite as a functional of matrix volume fraction perpendicular (a) and parallel (b) to the flow direction

men, $\Phi$ is the fibre content of the composite, and $m$ is the slope of the post shrinkage (time factor), $t$ $[1 ; 168 \mathrm{~h}]$.

\subsection{Light microscopy}

Figure 11 shows the single-fibre distributions in the specimens perpendicular to the flow direction (Front) near the gate. The distribution of single fibres is imperfect, and a skin-core structure formed.

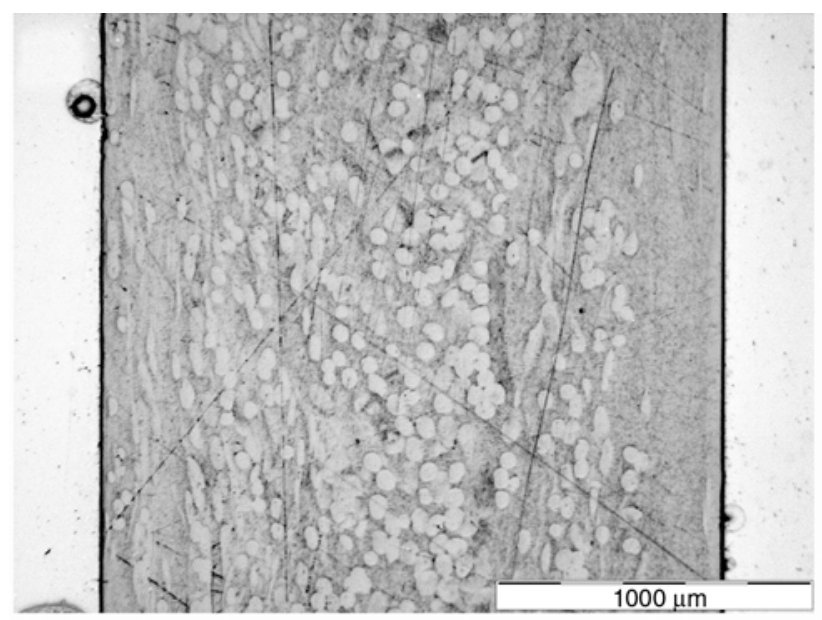

a)

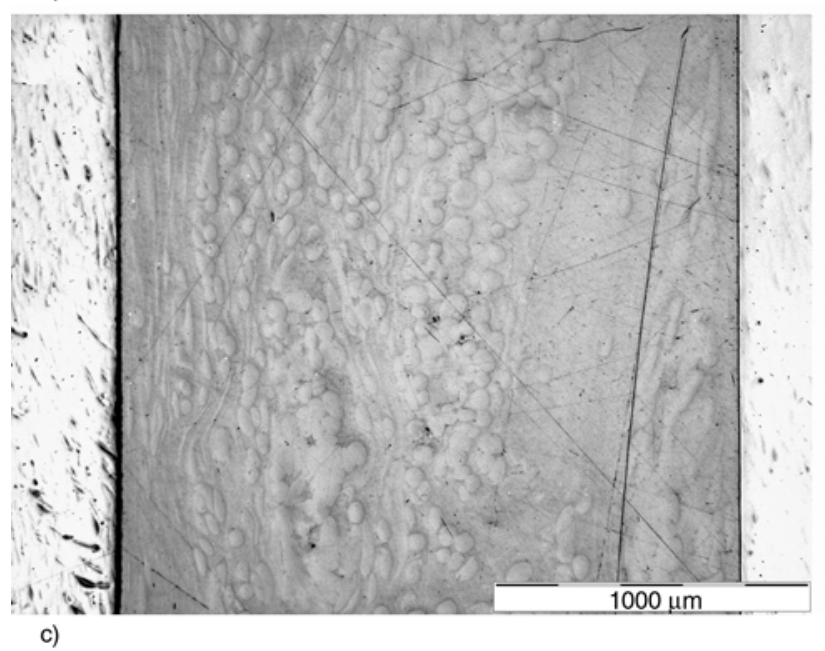

For $80 \mathrm{wt} \%$ fibre content, many more single fibres are aligned perpendicular to the flow direction, which significantly increased the tensile modulus (cf. Figure 6b).

LM images taken from the specimen cut in the flow direction (Side) are shown in Figure 12. A skin-core layer can also be found with a thickness that is similar to that of specimens cut perpendicular to the flow direction. For $80 \mathrm{wt} \%$ fibre content, there is

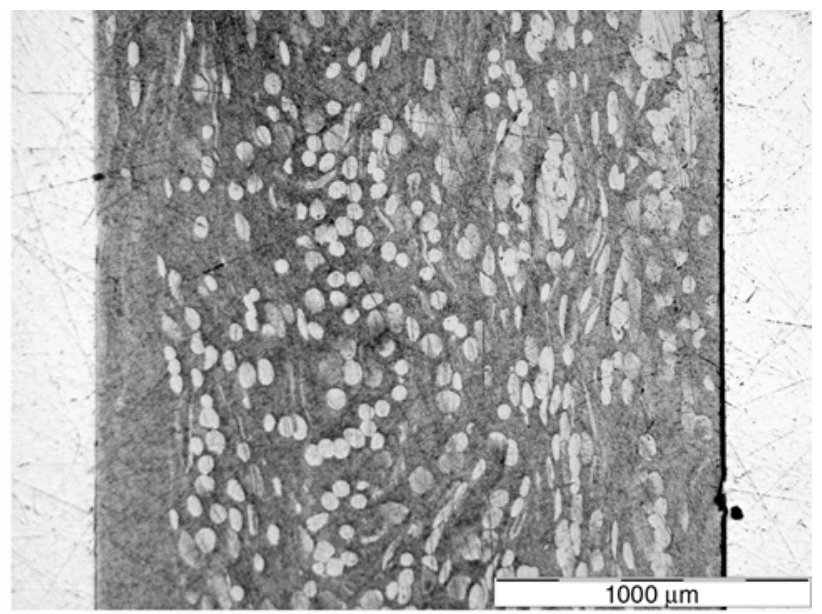

b)

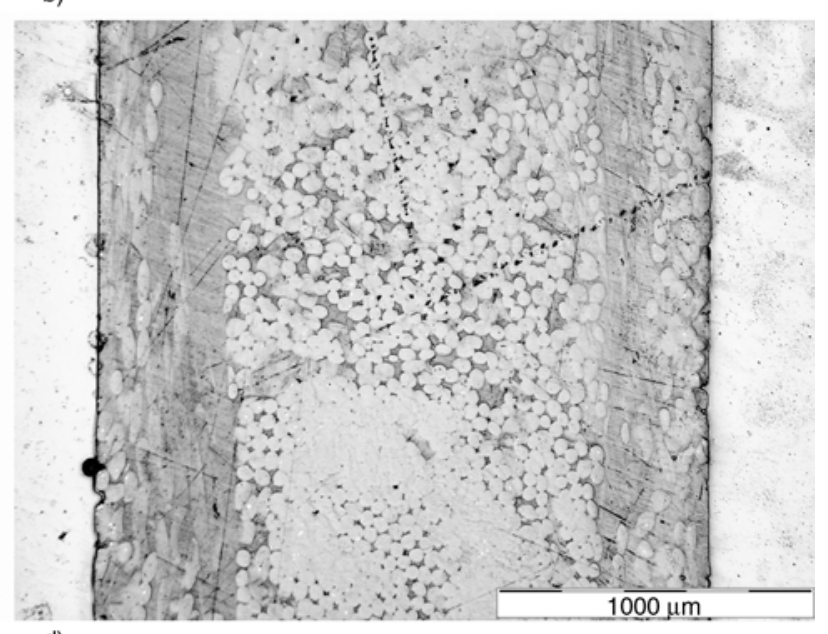

d)

Figure 11. LM micrographs of all-PP composites perpendicular to the flow direction (Front) a) $50 \mathrm{wt} \%$; b) $60 \mathrm{wt} \%$; c) $70 \mathrm{wt} \%$; d) $80 \mathrm{wt} \%$ 

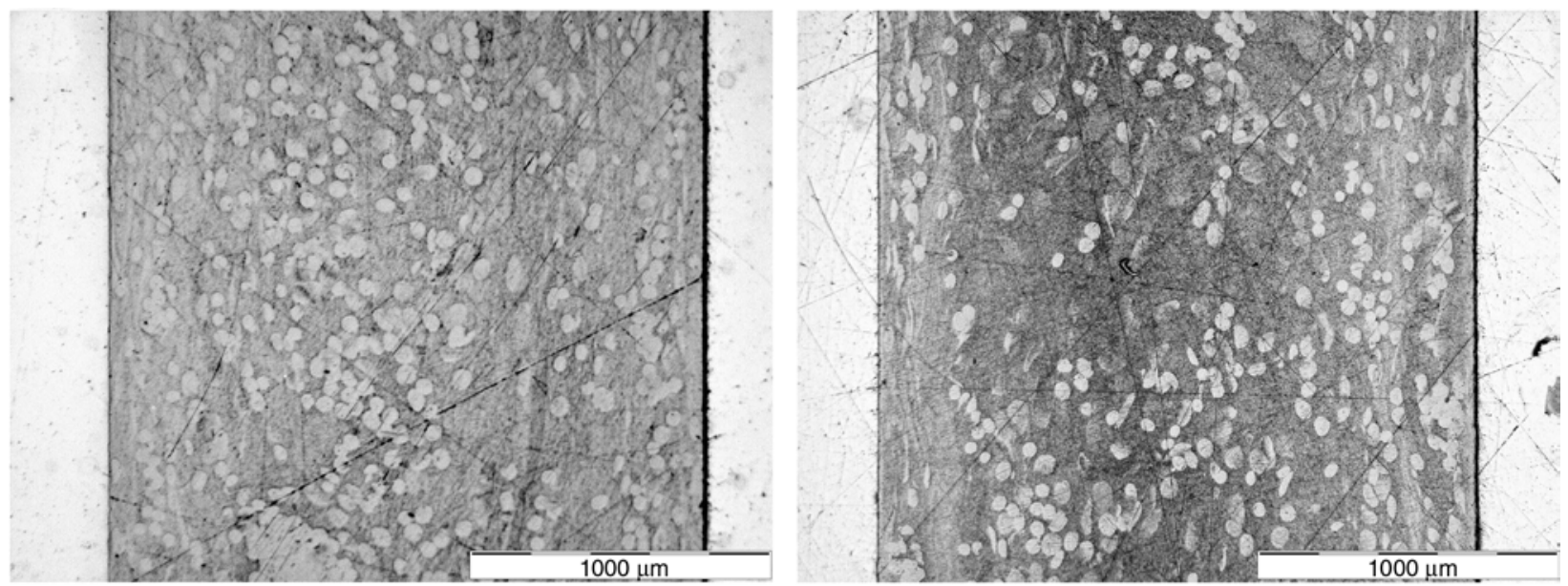

a)

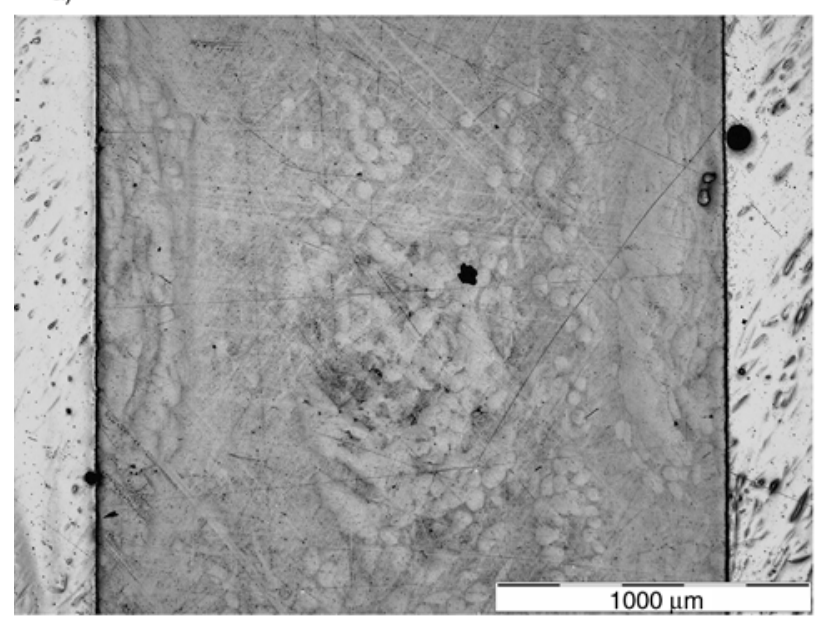

c) b)

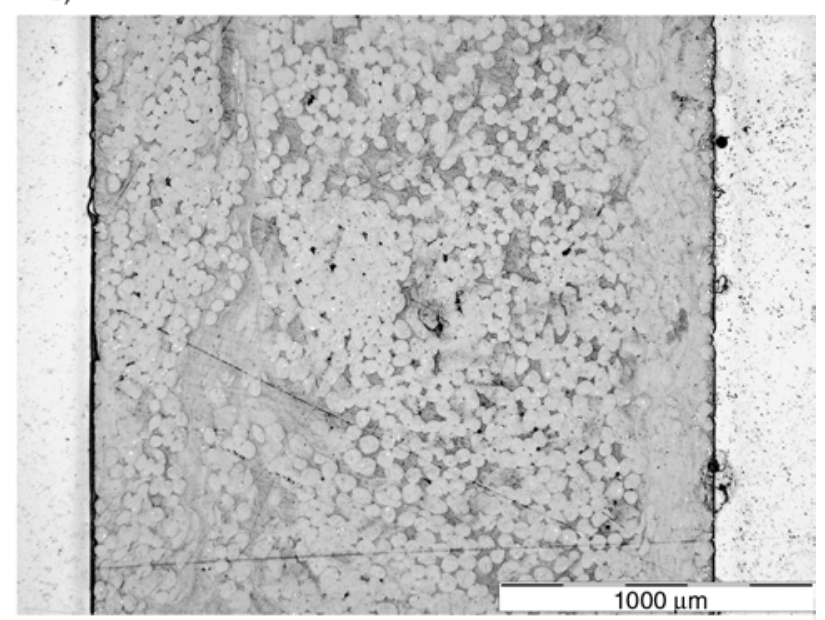

d)

Figure 12. LM micrographs of the all-PP composites in the flow direction (Side) a) $50 \mathrm{wt} \%$; b) $60 \mathrm{wt} \%$; c) $70 \mathrm{wt} \%$; d) $80 \mathrm{wt} \%$

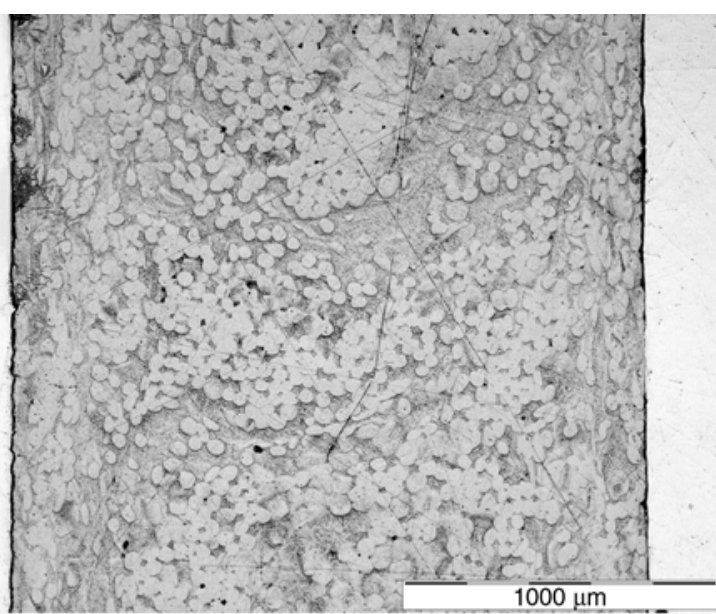

a)

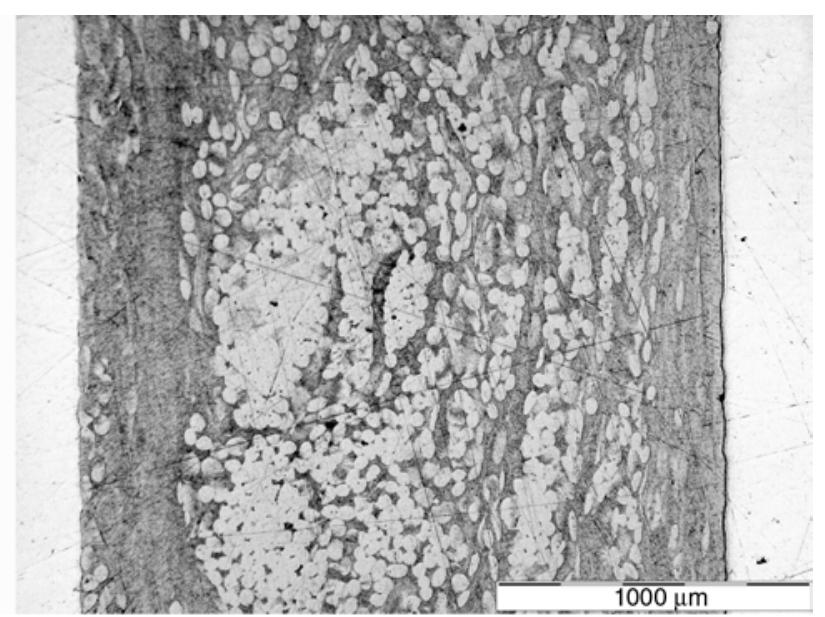

b)

Figure 13. LM micrographs of the all-PP composites ( $80 \mathrm{wt} \%)$ with fan gate perpendicular (a) and parallel (b) to the flow direction

better fibre distribution (Figure 12d) than for other composites, a trend similar to that in Figure 11d.

Perpendicular to the flow direction of the $80 \mathrm{wt} \%$ all-PP composites with a fan gate is presented in Figure 13. There is no skin layer formed perpendi- cular to the flow direction. Furthermore, the fibre distribution is better than that for the conventional film gate, which explains the improved mechanical properties. 


\subsection{Scanning electron microscopy (SEM)}

SEM micrographs were taken from the fracture surface of the all-PP composite specimens (Figure 14). The consolidation and fibre distribution worsened with increasing fibre content. Voids formed among the fibres because the matrix material could not impregnate the fibres. Moreover, for the $80 \mathrm{wt} \%$

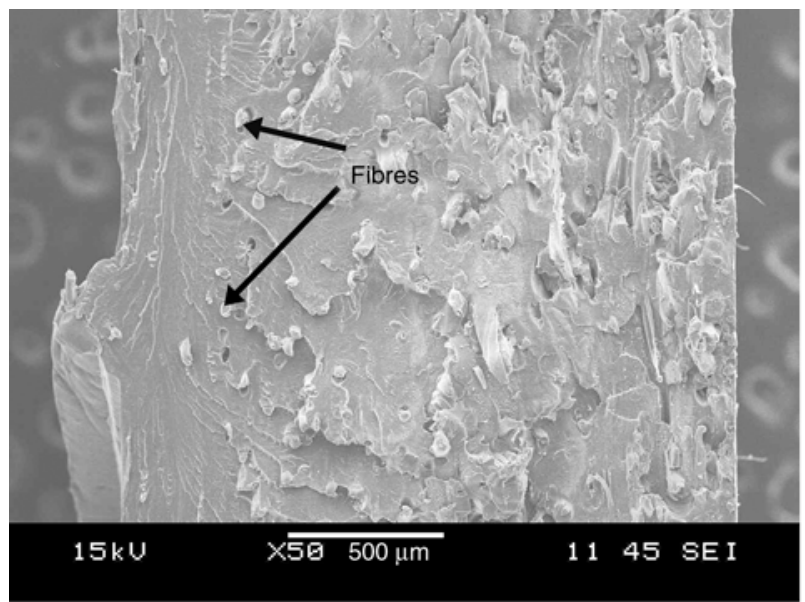

a)

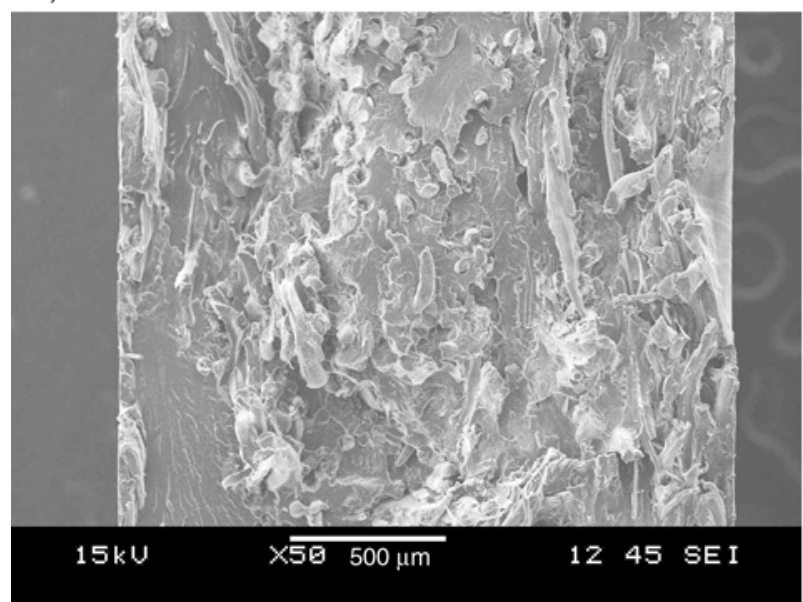

c) sample, there is poor adhesion between the matrix and fibres in the core region (Figure 14d).

Figure 15 shows the effect of the gate type used. With a fan gate, perpendicular to the flow direction of the specimen became more homogeneous, and the core could not be distinguished from the skin region.

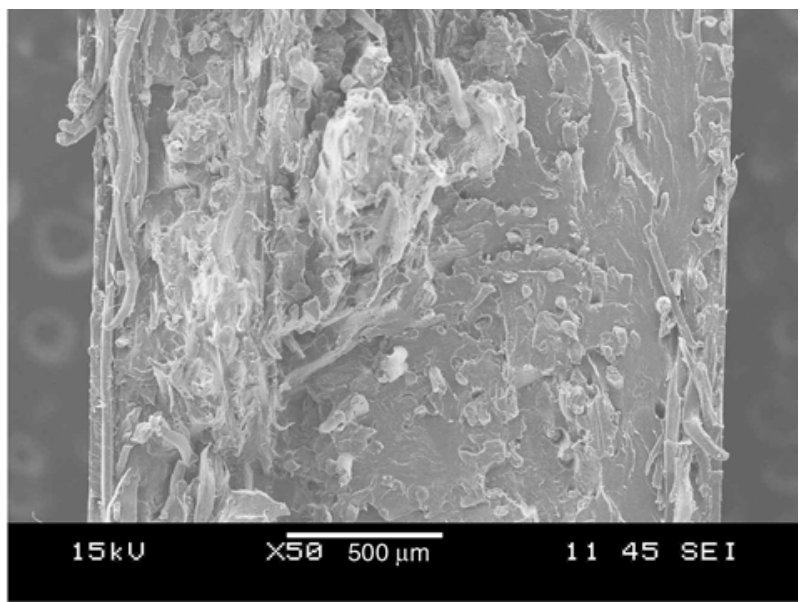

b)

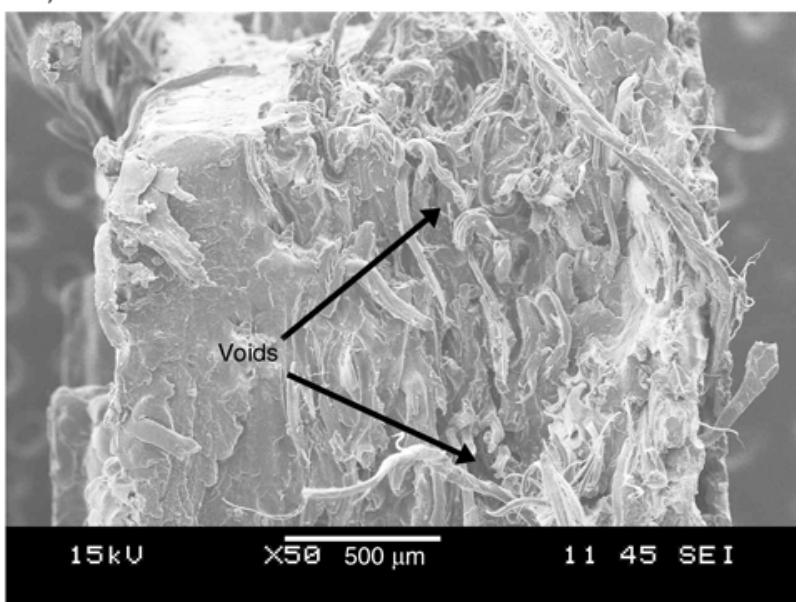

d)

Figure 14. Fracture surface of the all-PP composites a) $50 \mathrm{wt} \%$; b) $60 \mathrm{wt} \%$; c) $70 \mathrm{wt} \%$; d) $80 \mathrm{wt} \%$

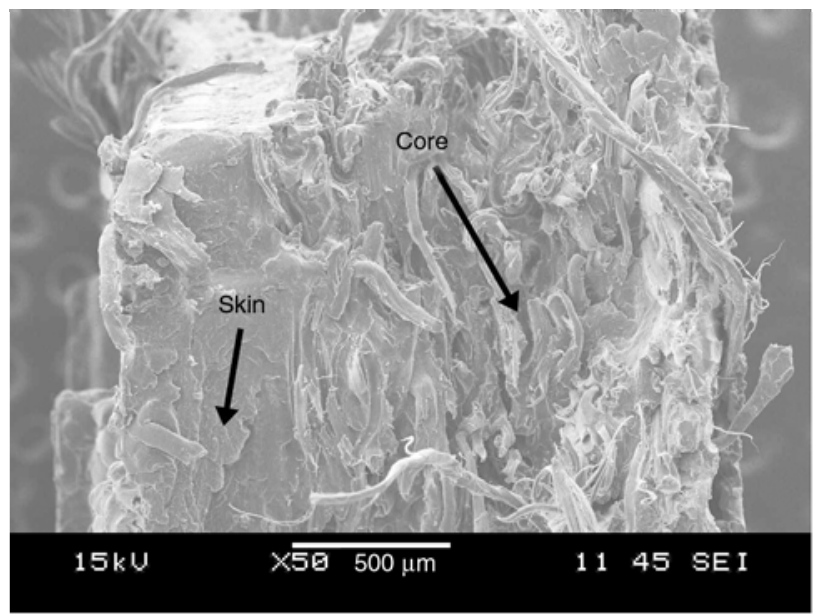

a)

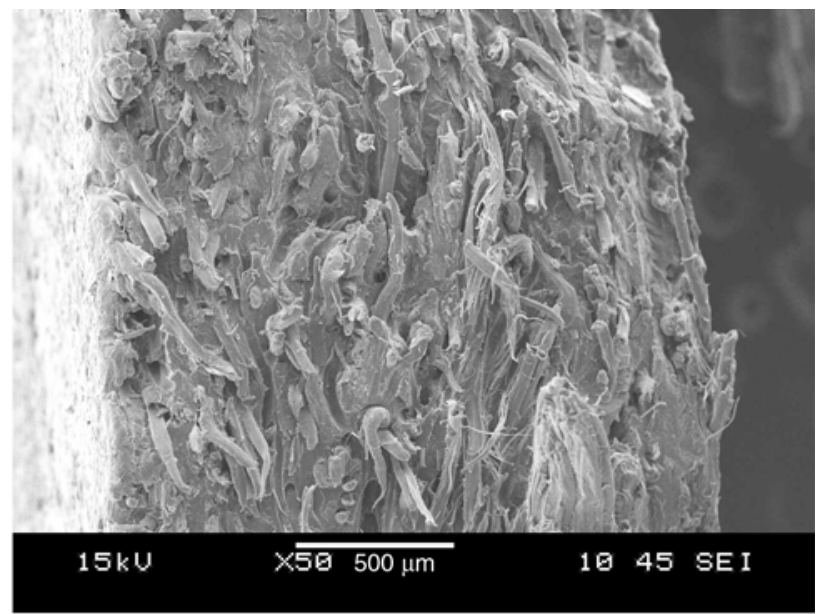

b)

Figure 15. Fracture surface of a composite prepared by a conventional film gate (a) and a fan gate (b) 


\section{Conclusions}

The goal of this paper was to study all-polypropylene composites that were produced by injection moulding. Static tensile tests, IFWI tests, DMA tests, shrinkage analysis, optical microscopy and scanning electron microscopy were carried out. The mechanical tests showed that increasing the fibre content (50-70 wt\%) of the pre-product the yield stress and perforation energy significantly increased. The applied fan gate resulted in more homogeneous tensile properties and greater perforation energy. Based on the results, all-PP composite showed greater shrinkage than the rPP matrix and the reinforcement did not decrease the shrinkage contrast to the conventional fibre reinforcement. This effect assumed to the relaxation of the thermoplastic reinforcement.

\section{Acknowledgements}

The authors are grateful to the Hungarian Scientific Research Fund (OTKA K75117).

T. Bárány is thankful for the János Bolyai Research Scholarship from the Hungarian Academy of Sciences. The work reported in this paper has been developed within the framework of the 'Talent care and cultivation in the scientific workshops of BME' project. This project is supported by the grant TÁMOP-4.2.2.B-10/1-2010-0009. This work is connected to the scientific program of the 'Development of quality-oriented and harmonized R+D+I strategy and functional model at BME' project. This project is supported by the New Széchenyi Plan (Project ID: TÁMOP-4.2.1/B09/1/KMR-2010-0002). The authors are grateful to Arburg Hungary Ltd. for the Arburg Allrounder 370S 700-290 machine.

\section{References}

[1] Capiati N. J., Porter R. S.: The concept of one polymer composites modelled with high density polyethylene. Journal of Materials Science, 10, 1671-1677 (1975). DOI: $10.1007 / \mathrm{BF} 00554928$

[2] Allan S. P., Bevis I. M., Zadhoush A.: The development and application of shear controlled orientation technology. Iranian Journal of Polymer Science and Technology, 4, 50-55 (1995).

[3] Ogbonna C. I., Kalay G., Allan P. S., Bevis M. J.: The self-reinforcement of polyolefins produced by shear controlled orientation in injection molding. Journal of Applied Polymer Science, 58, 2131-2135 (1995). DOI: 10.1002/app.1995.070581126

[4] Li Y., Chen J., Shen K.: Self-reinforced isotactic polypropylene prepared by melt vibration injection molding. Polymer-Plastics Technology and Engineering, 47, 673-677 (2008).

DOI: $10.1080 / 03602550802129551$
[5] Kmetty Á., Bárány T., Karger-Kocsis J.: Self-reinforced polymeric materials: A review. Progress in Polymer Science, 35, 1288-1310 (2010).

DOI: $10.1016 /$ j.progpolymsci.2010.07.002

[6] Pegoretti A.: Trends in composite materials: The challenge of single-polymer composites. Express Polymer Letters, 1, 710 (2007).

DOI: 10.3144 /expresspolymlett.2007.97

[7] Hine P. J., Ward I. M.: Hot compaction of woven nylon 6,6 multifilaments. Journal of Applied Polymer Science, 101, 991-997 (2006).

DOI: $10.1002 /$ app. 22771

[8] Hine P. J., Ward I. M.: Hot compaction of woven poly(ethylene terephthalate) multifilaments. Journal of Applied Polymer Science, 91, 2223-2233 (2004). DOI: 10.1002/app.13343

[9] Ward I. M.: Developments in oriented polymers, 19702004. Plastics Rubber and Composites, 33, 189-194 (2004). DOI: $\underline{10.1179 / 174328904 \times 4864}$

[10] Alcock B., Cabrera N. O., Barkoula N-M., Loos J., Peijs T.: The mechanical properties of unidirectional all-polypropylene composites. Composites Part A: Applied Science and Manufacturing, 37, 716-726 (2006).

DOI: 10.1016/j.compositesa.2005.07.002

[11] Chen J. C., Wu C. M., Pu F. C., Chiu C. H.: Fabrication and mechanical properties of self-reinforced poly (ethylene terephthalate) composites. Express Polymer Letters, 5, 228-237 (2011). DOI: $10.3144 /$ expresspolymlett.2011.22

[12] Izer A., Bárány T., Varga J.: Development of woven fabric reinforced all-polypropylene composites with beta nucleated homo- and copolymer matrices. Composites Science and Technology, 69, 2185-2192 (2009). DOI: 10.1016/j.compscitech.2009.06.002

[13] Pegoretti A., Zanolli A., Migliaresi C.: Flexural and interlaminar mechanical properties of unidirectional liquid crystalline single-polymer composites. Composites Science and Technology, 66, 1953-1962 (2006). DOI: 10.1016/j.compscitech.2006.01.015

[14] Dorigato A., Pegoretti A.: Biodegradable single-polymer composites from polyvinyl alcohol. Colloid and Polymer Science, 290, 359-370 (2012). DOI: $10.1007 / \mathrm{s} 00396-011-2556-\mathrm{Z}$

[15] Wu C. M., Chang C. Y., Wang C. C., Lin C. Y.: Optimum consolidation of all-polyester woven fabric-reinforced composite laminates by film stacking. Polymer Composites, 33, 245-252 (2012). DOI: $10.1002 / p c .22146$

[16] Matabola K. P., de Vries A. R., Luyt A. S., Kumar R.: Studies on single polymer composites of poly(methyl methacrylate) reinforced with electrospun nanofibers with a focus on their dynamic mechanical properties. Express Polymer Letters, 5, 635-642 (2011). DOI: $10.3144 /$ expresspolymlett.2011.61 
[17] Bhattacharyya D., Maitrot P., Fakirov S.: Polyamide 6 single polymer composites. Express Polymer Letters, 3, 525-532 (2009).

DOI: 10.3144/expresspolymlett.2009.65

[18] Pegoretti A., Zanolli A., Migliaresi C.: Preparation and tensile mechanical properties of unidirectional liquid crystalline single-polymer composites. Composites Science and Technology, 66, 1970-1979 (2006). DOI: 10.1016/j.compscitech.2006.01.012

[19] Prox M., Pornnimit B., Varga J., Ehrenstein G. W.: Thermoanalytical investigations of self-reinforced polyethylene. Journal of Thermal Analysis, 36, 1675-1684 (1990).

DOI: 10.1007/BF01913414
[20] Karger-Kocsis J., Wanjale S. D., Abraham T., Bárány T., Apostolov A. A.: Preparation and characterization of polypropylene homocomposites: Exploiting polymorphism of PP homopolymer. Journal of Applied Polymer Science, 115, 684-691 (2010).

DOI: 10.1002/app.30624

[21] Karian H. G.: Part shrinkage behavior of polypropylene resins and polypropylene composites. in 'Handbook of polypropylene and polypropylene composites' (eds.: H. G. Karian) Marcel Dekker, New York, Vol 19, 675-706 (2003). 